\title{
Historical analysis of suicide
}

\author{
Da-Yong Lu' ${ }^{1}$, Hong-Ying Wu${ }^{2}$, Shan $\mathrm{Cao}^{3}$, Jin-Yu Che ${ }^{1}$ \\ 'School of Life Science, Shanghai University, Shanghai 200444, China. \\ ${ }^{2}$ College of Science, Shanghai University, Shanghai 200444, China. \\ ${ }^{3}$ Kyoto University of Art \& Design, Kyoto 606-8271, Japan.
}

Correspondence to: Dr. Da-Yong Lu, School of Life Science, Shanghai University, Shanghai 200444, China.

E-mail: ludayong@shu.edu.cn

How to cite this article: Lu DY, Wu HY, Cao S, Che JY. Historical analysis of suicide. J Trans/ Genet Genom 2020;4:203-9. http://dx.doi.org/10.20517/jtgg.2020.33

Received: 14 May 2020 Accepted: 18 May 2020 Available online: 18 Jun 2020

Science Editor: Ramón Cacabelos Copy Editor: Cai-Hong Wang Production Editor: Jing Yu

\begin{abstract}
Suicide is a dangerous clinical event causing $2 \%$ of human mortality. Due to its inherent danger to life and complexity, suicide studies are in high demand. Many resources have been allocated to the development of predicting suicides, its prevention and useful medical interventions so that biomedical and scientific study of the subject is indispensable. Historically, knowledge on suicide was largely based on mental illness studies. The diagnosis of suicide,mood disorders and the treatments have been reported since over 2000 years ago (Hippocrates in 460-377, BC). Despite a long history of association between suicide and mood disorder, the related terminology have evolved greatly. Yet, mortality reduction has been minimal despite many diagnostic and therapeutic studies and no effective therapeutic means have been developed. To improve on this scenario, we review the history and literature on suicide.
\end{abstract}

Keywords: Suicide, psychiatric disease, mood disorder, terminology, diagnostics, mental illness, suicide mortality

\section{INTRODUCTION}

\section{Medical significance}

Suicide is a dangerous and complex event causing $2 \%$ of human mortality ${ }^{[1]}$. It remains an enigma and further studies on the topic are indispensable. Apart from mortality, huge resources have to be allocated towards the prediction, prevention and medical management of suicide. High-quality medical investigation of suicide is already underway ${ }^{[2-4]}$.

cc) (i) The Author(s) 2020. Open Access This article is licensed under a Creative Commons Attribution 4.0 International License (https://creativecommons.org/licenses/by/4.0/), which permits unrestricted use, sharing, adaptation, distribution and reproduction in any medium or format, for any purpose, even commercially, as long as you give appropriate credit to the original author(s) and the source, provide a link to the Creative Commons license, and indicate if changes were made. 
Table 1. Historic order of knowledge of mood disorder discovery (suicide associated) ${ }^{[8]}$

\begin{tabular}{ll}
\hline Timeline & \multicolumn{1}{c}{ Major discovery } \\
\hline Ancient Greece & Four elements and melancholy (excess of black bile) \\
Aretaeus of cappadocia & Clinical features of depression \\
Middle age & Patients with delusion \\
16th to 17th & Clinical diagnosis and abnormal behavior \\
18th & Nervous (animal spirits) \\
19th & Psychiatric symptoms \\
20th & Mood disorder, electroplexy and psychosurgery \\
\hline
\end{tabular}

\section{Suicidal study scenario}

Multiple different factors can lead to emergency situations with human suicide including environmental (external) and viral, drug or genetic factors (internal) ${ }^{[5]}$. It has recently been discovered that mental health problems may be a useful avenue for further clinical study of suicide including mood disorders, affective diseases, depressive disorders, and schizophrenia ${ }^{[6,7]}$. As a result, knowledge on suicide should be based both on scientific study and knowledge of mental illnesses.

\section{EARLY HISTORY}

\section{Earliest knowledge of human mental disease}

The diagnosis and treatment of suicide and mood disorders go back by more than 2000 years (Hippocrates in 460-377 BC $)^{[8,9]}$. From a long history of mood disorder studies, the diagnostic and therapeutic measures, especially terminology, have been gradually established. Yet, diagnostic and therapeutic controversies still remain. A great part of diagnosis and therapy in suicide and mood disorders is unsatisfactory. No targeted therapeutic drug is $100 \%$ effective although modern, supportive diagnostic systems have been established. To improve this scenario, the history and literature on suicide need to be carefully reviewed [Table 1].

\section{Social science for human suicide}

Human suicide has been reported for more than 3000 years for social knowledge. In ancient Greece, Egypt and Rome, suicide was not allowed and regarded as sinful. The victims' bodies would be abandoned in the wilderness and left to animals ${ }^{[10]}$. Only in 1,642 in the UK was it then accepted as a human illness. In recent times, society has gradually recognized that it is social inequality and poverty that drives human beings to kill themselves; thus, many social reforms have begun ${ }^{[10]}$.

\section{Statistics of suicide worldwide}

Worldwide, the statistics on human suicide are highly varied between countries such as Latin America ${ }^{[11]}$, Greece $^{[12]}$, Japan ${ }^{[13,14]}$, South Korea ${ }^{[14]}$, Europe ${ }^{[15]}$, Australia ${ }^{[16,17]}$ and the US ${ }^{[17]}$. Depending on the author. Comparing suicides across the world is difficult otherwise as there are many economical and political reasons ${ }^{[11-1]]}$. There is also great variation in the age and gender of human beings who attempt suicides. Thus, a deep understanding of the subject is required.

\section{MEDICAL KNOWLEDGE AND ADVANCES}

\section{Association between suicide and neuropsychiatry}

The causal factors of human suicide are arguable and remain widely disagreed. Currently, neuropsychiatric factors are recognized as one of the main culprits for human suicide events and mortality ${ }^{[6,7]}$. Table 2 shows a large clinical sample and data that display a strong association between risk of suicide and other mental health problems.

From a diagnostic aspect, the symptoms for risk of human suicide (feeling of hopelessness, self-blame and so on) are similar to those of mood disorders (hopelessness and helplessness). The external insults of the 
Table 2. The associations between suicide and other diseases ${ }^{[5,6]}$

\begin{tabular}{lclc}
\hline Worldwide; total of 15,629 cases & \multicolumn{2}{c}{ UK; total of 4,859 cases } \\
\hline Mood disorders & $35 \%$ & Mood disorders & $42 \%$ \\
Substance disorders & $22 \%$ & Schizophrenia & $20 \%$ \\
Personality disorders & $12 \%$ & Personality disorders & $11 \%$ \\
Schizophrenia & $11 \%$ & Alcohol dependence & $9 \%$ \\
Anxiety disorders & $6 \%$ & Drug dependence & $4 \%$ \\
& & Anxiety disorders & $3 \%$ \\
Other disorders & $14 \%$ & Other disorders & $11 \%$ \\
\hline
\end{tabular}

environment are also identical to factors behind mood disorders, including marriage problems and the loss of jobs or family members.

\section{Genetic and epigenetic factors}

As there have yet to be any conclusive outcome on the pathogenesis of suicide, high-quality biomedical studies (genetic, molecular and cerebral imaging) are currently utilized for suicide prediction, prevention and therapeutics ${ }^{[1,18-26]}$. It therefore supported the previous, hypothetical link between suicide and mental health problems through genetic and molecular analysis. As a result, more information associated with the diagnosis of mental diseases can be used for suicide risk prediction, prevention and treatment.

\section{Mental illness pathology and evolution of diagnostics from history}

Mood disorders are an old and serious type of disease. In an ancient discovery, it was first noticed and described by ancient Greek physicians more than 2000 years ago (Hippocrates, $460-377 \mathrm{BC})^{[8,9]}$. As a main symptom of mental disorder, suicide has a high mortality rate throughout the world. During Hippocrates' time, he found a symptom of "melancholia", known today as "depression", and associated the disease with human "brain dysfunction". A thousand years have passed and these statements have not been seriously challenged. We believe that this observation is still the core of future scientific and medical investigations.

The quest for a relationship between suicide and mental illness has lasted from ancient times to the modern era. Despite the long history of suicide and mental illness studies, diagnostics are especially limited - act and symptoms (suicide attempts and repeats) and is a current area of research emphasis ${ }^{[1,18-26]}$. Human suicides were previously treated and controlled with relevant chemical drugs, such as antidepressants ${ }^{[26-31]}$. However, these drug therapies work like a double-edged sword that has both strengths and weaknesses. To overcome this setback, new therapeutics must be made.

\section{CURRENT ACHIEVEMENTS IN DIAGNOSTICS AND TREATMENT}

\section{Current routine in neuropsychiatric diagnostics}

Formally, diagnostic guidelines have been established and widely applied worldwide. Detailed diagnostic information can be found in the Diagnostic and Statistical Manual of Mental Disorders (DSM) from DSM-I to DSM-V of mental problems and the Hamilton Depression Rating Scale (HAM-D) of suicide risk.

\section{Progress in genetic and molecular technology for diagnosis}

Psychiatric analysis is currently used as diagnostic means by clinicians and psychiatrists. Medications are prescribed after analyzing the patient's psychiatric condition (different types of psychiatric illness scoring systems for depressive or manic symptoms) rather than the patient's genetic predisposition such as pharmacogenetics (PG), genomic sequencing, bioinformatic profiling or brain image/visual comparisons. They analyze patients through disease symptoms (suicide episodes) that mask the most important parts of disease origination and progress (genetic/molecular-based causalities) in a series of pathogenesis stages or suicide-induced mortality. Over the long history of suicide and mental illness studies, quick and proper diagnosis is key. More recently, the morphological or visual scan of human brains of patients at 


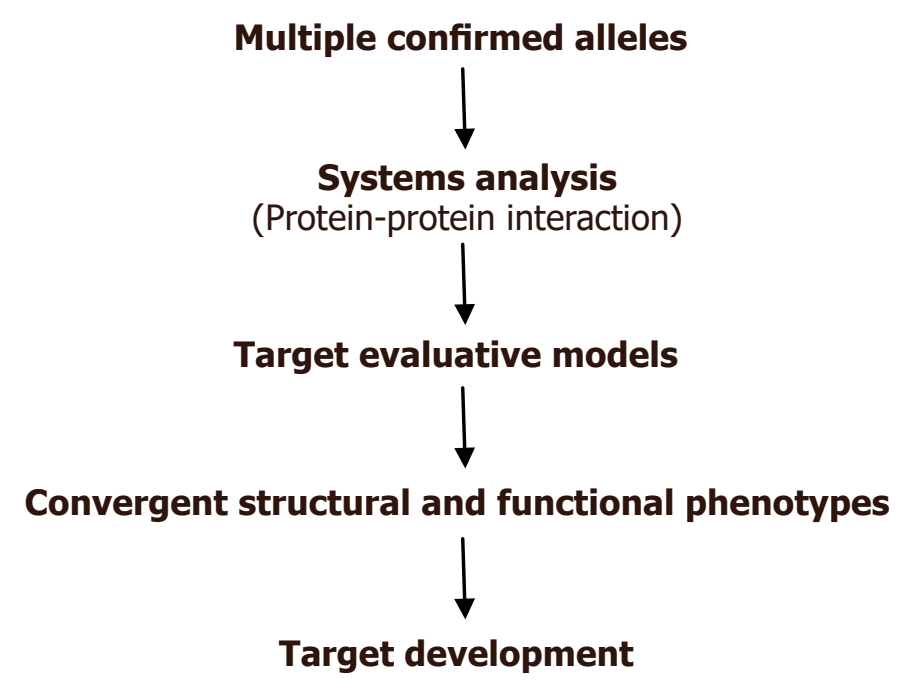

Figure 1. Therapeutic and drug design development

high suicide risk have begun to emerge for determining disease progression or multi-factorial etiological identification ${ }^{[18-26]}$.

The genetic changes in psychiatric diseases are enormous, such as UNC13A, NFASC, PTPRG, ERBB2, GR1N2A, HTR2A, DLG, ACTN, MYH9 and many others ${ }^{[32,33]}$. So far, at least 400 human genes are involved in neuropsychiatric disorders and much more scientific research is needed.

\section{Toxicity of antidepressants}

Antidepresssants have been implicated as inducers of human suicide and has been reported with mechanistic investigation. We have previously studied and discussed drug toxicity from a genetics perspective. Our proposition is that some patients with genetic deficiencies may develop an over-reaction to antidepressants and induce human suicide ${ }^{[26]}$. This can explain the clinical suicides that are evidenced in only a small number of patients receiving antidepressants. Most patients are otherwise safe with antidepressant medication.

\section{Neuropathy}

To provide a high-quality platform for human suicide study, neuropathic processes may be understood ${ }^{[34-36]}$. These complex processes have been explored over the past two decades due to technical updating (genetic or morphology). Many specific neural structural or functional elements or areas have been studied. This interesting topic may be a fruitful discipline in the upcoming decades worldwide.

\section{Therapeutic study and drug development}

Therapeutic studies for neuropsychiatric diseases have increased greatly. Possible therapeutic and drug design pathways are given in Figure 1. In this stage, antidepressants (selective serotonin reuptake inhibitor, SSRI) are widely utilized in clinical trials and show therapeutic outcomes and benefits clinically ${ }^{[30]}$.

Apart from drug treatment, other types of therapies, such as light therapy (physical treatment) are also useful for mood disorders or suicidal patients ${ }^{[37]}$. In Scandinavia, there is a seasonal shift in human suicides or rates of mood disorders every year. Light therapy could help these special types of patients in the winter of each country in Scandinavia. 


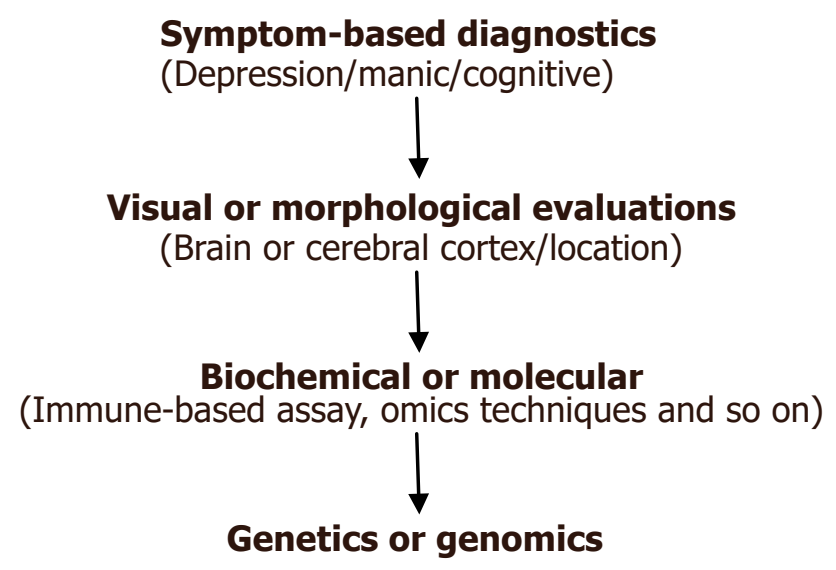

Figure 2. Evolution of diagnostics in suicide and mental disorders ${ }^{[2]}$

\section{FUTURE DIRECTIONS}

There are several future directions for optimizing genetic/molecular-based diagnostics for suicide prediction and prevention. From these efforts, a patient's suicide risk may be quickly understood via high throughput and low cost diagnostics. Targeted drug therapeutics or other types of specific, highly effective interventions can then be clinical implemented [Figure 2].

(1) Scientific testing, scoring and computational networks for clinical data relationship buildup between disease causalities, progression, mortality and possible drug targeting;

(2) Comparisons of different scoring algorithms or calculation systems and customization of several workable paradigms for future clinical personalized medicine application;

(3) Establishment of the relationship between clinical diagnosis and treatment via modern technique-based ways (from genetic to molecular to visual or from visual to molecular or genetics);

(4) Increasing the accumulation of clinical genetic or molecular data ( $>5000$ clinical cases between patients at high suicide risk and normal persons);

(5) Collecting and evaluating data from the diagnostic relationship between genetic polymorphisms, chemical and environmental factors of multiple disciplines ${ }^{[32-41]}$.

\section{CONCLUSION}

The prediction and prevention of human suicide, especially in diagnostics, must be greatly promoted and improved. Much work is still needed in the clinic, including clinical diagnosis and effective, targeted drugs for the safeguarding of patients at high suicide risk.

\section{DECLARATIONS}

Authors' contributions

Article writing: Lu DY, Cao S

Data collection and analysis: Wu HY, Che JY

Availability of data and materials

Not applicable.

Financial support and sponsorship

None. 


\section{Conflicts of interest}

All authors declared that there are no conflicts of interest.

\section{Ethical approval and consent to participate}

Not applicable.

\section{Consent for publication}

Not applicable.

\section{Copyright}

(c) The Author(s) 2020.

\section{REFERENCES}

1. Bondy B, Buettner A, Zill P. Genetics of suicide. Mol Psychiatry 2006;11:336-51.

2. Lu DY. Suicide risks and treatments, new ideas and future perspectives. New York, US: Nova Science Publishers; 2017.

3. Serafini G, Salano P, Amore M. Suicidal ideation: a comprehensive overview. Bradley Weaver. US: Nova Science Publishing; 2015. pp. $1-42$.

4. Lu DY, Lu TR, Lu Y, Cao S. Introduction for suicide study. J Metab Syndr 2017;6:227.

5. Lu DY, Lu TR, Zhu PP, Che JY. The efficacies and toxicities of antidepressant drugs in clinics, building the relationship between ChemoGenetics and Socio-Environments. Cent Nerv Syst Agents Med Chem 2016;16:12-8.

6. Marreros A. Mood disorders: epidemiology and natural history. Psychiatry 2008;8:52-5.

7. Lu DY, Zhu PP, Wu HY, Yarla NS, Zhu H, et al. Human suicide study, is there an association between suicide and mental illness. Metabolomics 2016;6:186.

8. Davison K. Historical aspects of mood disorders. Psychiatry 2006;5:115-8.

9. Lu DY, Wu HY, Cao S, Lu Y, Yarla NS, et al. Historical analysis of suicide/mental disorder and current diagnostics in clinics. Suicide Risks and Treatments, New Ideas and Future Perspectives. New York, US: Nova Science Publishers; 2017. pp. 1-12.

10. Shandilya S. Suicide and suicide prevention: a historical review. Res J Social Sci 2018;9:35-40.

11. Azuero AJ, Arreaza-kaufman D, Caria J, Tasinari S, Faria A, et al. Suicide in the indigenous population of Latin America: a systematic review. Availabel from: http://dx.doi.org/10.1016/j.rcp.2016.12.002. [Last accessed on 4 Jun 2020]

12. Fountoulakis KN. Suicide rate in Greece stabilizes at historically high levels but still lowest in Europe. J Affect Disord 2019;254:117-9.

13. Dhungel B, Sugai MK, Gilmour S. Trends in suicide mortality by methods from 1979 to 2016 in Japan. Int J Environmental Res Public Health 2019;16:1794.

14. Kino S, Jang SN, Gero K, Kato S, Kawachi I. Age, period, cohort, trends of suicide in Japan and Korea (1986-2015): a tale of two countries. Soc Sci Med 2019;235:112385.

15. McNicolas F. Suicide in Europe: an on-going public health concern. Soc Psihijat 2017;45:22-9.

16. Snowdon J, Phillips J, Zhong BL, Yamauchi T, Chiu HFK, et al. Changes in age patterns of suicide in Australia, the United States, Japan and Hong Kong. J Affect Disord 2017;211:12-9.

17. Steelesmith D, Fontanella CA, Campo JV, Bridge JA, Warren KL, et al. Contextural factors associated with county-level suicide rates in the United States, 1999 to 2016. JAMA 2019;2:e1910936.

18. Lu DY, Lu TR, Zhu PP, Che JY. Genetics and bioinformatics study of antidepressant drugs, recent advancements and future trends. Bradley Weaver. US: Nova Science Publishing; 2015. pp. 57-71.

19. While D, Bickley H, Roscoe A, Windfuhr K, Rahman S, et al. Implementation of mental health service recommendations in England and Wales and suicide rates, 1997-2006: a cross-sectional and before-and-after observational study. Lancet 2012;379:1005-12.

20. Frangou S. Brain structural changes in mood disorders. Psychiatry 2009;8:105-6.

21. Roiser JP, Rubinsztein JS, Sahakian BJ. Neuropsychology of affective disorders. Psychiatry 2009;8:91-6.

22. Frangou S. Functional neuroimaging in mood disorder. Psychiatry 2008;6:102-4.

23. Desmyter S, Bijttebier S, Heeringen KV. The role of neuroimaging in our understanding of the suicidal brain. CNS Neurol Disord Drug Targets 2013;12:921-9.

24. Lu DY, Lu TR, Yarla NS, Wu HY. Genetics in suicide treatments, modern diagnosis establishments. J Mental Disord Treat 2017;3:145.

25. Kendell R. Diagnosis and classification of mood disorders. Psychiatry 2006;5:112-4.

26. Lu DY, Lu TR, Che JY, Zhu PP. Genetics and bioinformatics studies of antidepressant drug therapeutic efficacies and toxicities, a current overview. Recent Pat CNS Drug Discov 2014;9:193-9.

27. McAllister-Williams R, Ferrier IN. Pharmacological management of unipolar affective disorder. Psychiatry 2009;8:113-9.

28. McAllister-Williams R, Ferrier IN. Pharmacological management of bipolar affective disorder. Psychiatry 2009;8:120-4.

29. Lucas, G. Fast-acting antidepressants: are we nearly there. Expert Rev Neurotherapeutics 2008;8:1-3.

30. Menchetti M, Bortolotti B, Rucci P, Scocco P, Bombi A, et al. Depression in primary care: Interpersonal counseling vs selective serotonin reuptake inhibitors. The DEPICS study. A multicenter randomized controlled trial. Rationale and design. BMC Psychiatry $2010 ; 10: 97$. 
31. Menchetti M, Rucci P, Bortolotti B, Bombi A, Scocco P, et al. Moderators of remission with interpersonal counseling or drug treatment in primary care patients with depression: randomized controlled trial. Br J Psychiatry 2014;204:144-50.

32. Malhotra D, Sebat J. CNVs: harbingers of a rare variant revolution in psychiatric genetics. Cell 2012;148:1223-41.

33. Krystal JH, State MW. Psychiatric disorders: diagnosis to therapy. Cell 2014;157:201-14.

34. Desmyter S, Bijttebier S, Heeringen KV. The role of neuroimaging in our understanding of the suicidal brain. CNS Neurol Disord Drug Targets 2013;12:921-9.

35. Lu DY, Zhu PP, Wu HY, Yarla NS, Xu B, et al. Human suicide risk and treatment study. Cent Nerv Syst Agents Med Chem 2018;18:206-12.

36. Lu DY, Che JY, Wu HY, Lu TR, Putta S. Suicide risks and prevention, neuropathogenic study. Edeweiss Psyi Open 2020;4:124.

37. Eagles JM. Light therapy and seasonal affective disorder. Psychiatry 2009;8:125-9.

38. Cao S, Lu DY, Lu TR, Yarla NS. Future directions in the field of suicide study. EC Orthopaedics 2017;6:206-8.

39. Lu DY, Lu TR, Zhu PP. Undesired neural side-effects of a drug, a chemical and genetic interrelated problem. Cent Nerv System Agent Med Chem 2010;10:108-12.

40. Lu DY, Yarla NS, Lu TR, Varki A, Xu B, et al. Pathology and medication for human suicide. Cell Dev Biol 2019;8:201.

41. Lu DY, Zhu PP, Lu TR, Che JY. The suicidal risks and treatments, seek medications from multi-disciplinary. Cent Nerv Syst Agents Med Chem 2016;16:231-9. 